\title{
FAKTOR-FAKTOR YANG BERHUBUNGAN DENGAN HEALTH LITERACY PADA MAHASISWA KEPERAWATAN DI UNIVERSITAS UDAYANA DENPASAR, BALI
}

\author{
Made Dwi Mohini ${ }^{1}$, Ni Komang Ari Sawitri ${ }^{2}$, IGA Pramitaresthi ${ }^{3}$ \\ ${ }^{1}$ Mahasiswa Program Studi Sarjana Keperawatan dan Profesi Ners, Fakultas Kedokteran Universitas Udayana. \\ ${ }^{2,3}$ Dosen Program Studi Sarjana Keperawatan dan Profesi Ners, Fakultas Kedokteran Universitas Udayana. \\ Alamat korespondensi: mademohini5@gmail.com
}

\begin{abstract}
ABSTRAK
Health literacy adalah salah satu penentu kesehatan. Kurangnya partisipasi perawatan kesehatan, penggunaan pelayanan preventif, dan partisipasi dalam penerapan perilaku hidup sehat berhubungan dengan rendahnya health literacy seseorang. Health Literacy pada mahasiswa keperawatan perlu diperhatikan karena mahasiswa keperawatan merupakan calon tenaga kesehatan masa depan yang memiliki peran vital sebagai edukator. Penelitian ini memiliki tujuan adalah untuk mengkaji faktor yang berhubungan dengan health literacy pada mahasiwa keperawatan di Universitas Udayana. Penelitian ini berjenis deskriptif dan korelasional dengan menggunakan pendekatan cross-sectional. Teknik Proportionate Stratified Random Sampling digunakan pada penelitian ini dan penelitian dilakukan pada 148 responden dari empat semester yang berbeda. Instrumen yang digunakan dalam penelitian adalah formulir karakteristik responden dan Short-Form Health Literacy Survey Tool (HLS-SF-12). Uji analisis Deskriptif Statistik, Tendensi Sentral, Korelasi Gamma dan Koefisien Kontingensi digunakan pada penelitian ini. Hasil uji statistik menunjukkan bahwa tingkat semester, jenis kelamin, tingkat pendidikan tertinggi orangtua, keberadaan masalah kesehatan dengan health literacy, dan frekuensi penggunaan internet untuk tujuan kesehatan tidak berhubungan dengan tingkat health literacy mahasiswa keperawatan di Universitas Udayana ( $\mathrm{p}>0,05$ ). Mahasiswa keperawatan di Universitas Udayana dengan health literacy rendah. Berdasarkan hasil penelitian, disarankan kepada staf pengajar untuk lebih memperhatikan dan mengintegrasikan health literacy ke dalam proses pembelajaran mahasiswa keperawatan seperti pada mata kuliah promosi kesehatan.
\end{abstract}

Kata Kunci: Health literacy, Mahasiswa Keperawatan, Pendidikan Keperawatan.

\begin{abstract}
Health literacy is one of health determinants. Low use of healthcare, preventine services, and less participation of health promoting behaviours are associated with low level of health literacy. Health literacy levels of nursing students are important because nursing student is a future healthcare profesional who has vital role as an educator. The aimed of this study is to asses the related factors of health literacy of nursing student in Udayana University. The study types is descriptive correlative with cross-sectional approach. Proportionate Stratified Random Sampling was applied and this study conducted with 148 participants from four different grades. This study used Participants Characteristic Form and Short-Form Health Literacy Survey Tool (HLS-SF-12) as data collection tool. Descriptive statistics, Central Tendency, Gamma correlation analysis, and Contingency Coefficent correlation analysis were used for data analysis. The result of statistic test showed that no significant correlation between grades, gender, parents highest educational level, presence of health problem, and frequency of internet use for health purposes with health literacy $(\mathrm{p}=0,232)$ of nursing student in Udayana University. Nursing students in Udayana University have a low level of health literacy. Health literacy levels of nursing student play an important role for their health and role as health professional in the future. Based on this study result, it is suggest for nursing lecturer to intergrated and addressed health literacy into student learning process like include health literacy in health promotion subject.
\end{abstract}

Keyword : Health Literacy, Nursing Education, Nursing Student. 


\section{PENDAHULUAN}

Health literacy merupakan salah satu konsep promosi kesehatan, yang dianggap sebagai salah satu tujuan sistem kesehatan masyarakat abad ini. Health Literacy berkaitan dengan kemampuan atau kompetensi seseorang dalam melakukan akses informasi, kemudian memahami dan menganalisa informasi yang didapatkan untuk mengambil keputusan yang tepat dalam kehidupannya baik dalam tatanan perawatan kesehatan pencegahan penyakit, atau promosi kesehatan dengan tujuan menjaga atau meningkatkan status kesehatannya (Sørensen, et al., 2012).

Topik health literacy penting untuk diperhatikan karena health literacy seseorang dapat memengaruhi kemampuannya dalam mempertahankan atau meningkatkan kesehatan. Kesulitan yang dialami menyebabkan seseorang cenderung mengambil keputusan yang berisiko terhadap kesehatan seperti kurangnya partisipasi terhadap promosi kesehatan dan aktivitas-aktivitas yang berhubungan dengan deteksi dini penyakit atau pencegahan penyakit ( Kickbusch, et al., 2013).

calon $\begin{gathered}\text { Mahasiswa keperawatan sebagai } \\ \text { tenaga kesehatan yang }\end{gathered}$ bertanggungjawab untuk menyediakan pendidikan kesehatan kepada klien, harus menyadari pentingnya health literacy (Kennard, 2016). Health literacy mahasiswa keperawatan penting untuk diperhatikan, tidak hanya memengaruhi perannya sebagai health educator, namun juga kemampuaannya dalam mengambil keputusan yang tepat untuk kesehatannya. Penelitian yang dilakukan di Slovenia menyebutkan bahwa health literacy berhubungan dengan perilaku hidup sehat mahasiswa keperawatan. Mahasiswa keperawatan dengan health literacy yang adekuat cenderung akan lebih jarang minum alkohol, sarapan setiap hari, dan memiliki berat badan yang normal (Kolnik, Dejan, \& Katarina, 2017).

Health literacy berhubungan dengan beberapa faktor yang membuat tingkat health literacy berbeda pada masing-masing individu. Penelitian sebelumnya menyebutkan bahwa tingkat semester (Erunal, et al., 2019), jenis kelamin (Uysal, et al., 2019), tingkat pendidikan tertinggi orangtua (Zhang, et al., 2016), keberadaan masalah kesehatan (Ayaz-Alkaya \& Terzi, 2019), dan frekuensi penggunaan internet untuk tujuan kesehatan (Park \& Lee, 2015) berhubungan dengan health literacy. Penelitian ini bertujuan untuk mengakses faktor yang berhubungan dengan health literacy pada mahasiswa keperawatan di Universitas Udayana.

\section{METODE PENELITIAN}

Penelitian ini berjenis deskriptif korelasional menggunakan pendekatan cross-sectional. Populasi penelitian adalah 250 mahasiswa keperawatan di Universitas Udayana. Kriteria inklusi pada penelitian ini adalah mahasiswa keperawatan semester 2,4,6,8 di Universitas Udayana Kriteria eksklusi pada penelitian adalah mahasiswa keperawatan yang sedang cuti akademik.

Data dikumpulkan dengan menggunakan kuesioner karakteristik individu dan Short-Form Health Literacy Survey Tool (HLS-SF-12) versi bahasa Indonesia dan sudah diuji validitas $(0,923)$ dan reabilitas $(0,923)$ (Setyawan, 2017).

Pengumpulan data dilakukan secara online dengan menyebarkan kuesioner secara personal melalui pesan di sosial media line. Skor dari 12 item pertanyaan pada kuesioner HLS-SF-12 dijumlahkan kemudian dirata-ratakan dan diubah menjadi skor 0-50 dengan menggunakan formula seperti berikut : (mean-1) x (50/3) (Duong, et al., 2017). 
Analisis univariat data kategorik seperti jenis kelamin, tingkat semester, tingkat pendidikan tertinggi orangtua, keberadaan masalah kesehatan, dan frekuensi penggunaan internet untuk tujuan kesehatan menggunakan analisis distribusi frekuensi, sedangkan data usia dianalisis dengan tendensi sentral.

Analisis bivariate hubungan antara tingkat semester, tingkat pendidikan tertinggi orangtua, dan frekuensi penggunaan internet untuk tujuan kesehatan dengan health literacy digunakan uji korelasi gamma. Analasis hubungan antara jenis kelamin dan keberadaan masalah kesehatan dengan health literacy digunakan uji korelasi koefisien kontingensii. Tingkat kepercayaan uji analisis korelatif adalah $95 \%(\mathrm{p} \leq 0,05)$.

\section{HASIL PENELITIAN}

Tabel 1 dan 2 memperlihatkan hasil dari karakteristik mahasiswa keperawatan di Universitas Udayana. 
Tabel 1.

Karakteristik Mahasiswa Keperawatan di Universitas Udayana

\begin{tabular}{|c|c|c|}
\hline Karakteristik & $\mathbf{n}$ & $\%$ \\
\hline \multicolumn{3}{|l|}{ Jenis Kelamin } \\
\hline Laki-laki & 23 & 15,5 \\
\hline Perempuan & 125 & 84,5 \\
\hline Total & 148 & 100 \\
\hline \multicolumn{3}{|l|}{ Tingkat Semester } \\
\hline 2 & 44 & 29,7 \\
\hline 4 & 34 & 23 \\
\hline 6 & 37 & 25 \\
\hline 8 & 33 & 22,3 \\
\hline Total & 148 & 100 \\
\hline \multicolumn{3}{|c|}{ Tingkat Pendidikan Tertinggi Orangtua } \\
\hline $1 \quad$ Tidak sekolah & 2 & 1,4 \\
\hline Pendidikan dasar (SD-SMP) & 12 & 8,1 \\
\hline SMA & 66 & 44,6 \\
\hline Perguruan tinggi & 68 & 45,9 \\
\hline Total & 148 & 100 \\
\hline \multicolumn{3}{|l|}{ Keberadaan Masalah Kesehatan } \\
\hline Ya & 42 & 28,4 \\
\hline Tidak & 106 & 71,6 \\
\hline Total & 148 & 100 \\
\hline
\end{tabular}

Frekuensi penggunaan internet dengan tujuan kesehatan

\begin{tabular}{llcc}
\hline 1 & $1-3$ kali sebulan & 25 & 16,9 \\
\hline 2 & 1 kali seminggu & 12 & 8,1 \\
\hline 3 & Beberapa kali seminggu & 70 & 47,3 \\
\hline 4 & Kurang dari 3 kali sehari & 15 & 10,1 \\
\hline 5 & Lebih dari 3 kali sehari & 26 & 17,6 \\
\hline & Total & 148 & 100
\end{tabular}

Tabel 2.

Karakteristik Mahasiswa Keperawatan di Universitas Udayana berdasarkan Usia

\begin{tabular}{|c|c|c|c|c|c|}
\hline Usia & Frekuensi (n) & $\%$ & Mean & Min & Max \\
\hline 118 & 5 & 3,4 & 20,11 & 18 & 24 \\
\hline 19 & 50 & 33,8 & & & \\
\hline 20 & 39 & 26,4 & & & \\
\hline 21 & 34 & 23 & & & \\
\hline 22 & 18 & 12,2 & & & \\
\hline 23 & 1 & 0,7 & & & \\
\hline 24 & 1 & 0,7 & & & \\
\hline & 148 & 100 & & & \\
\hline
\end{tabular}


Berdasarkan tabel karakteristik mahasiswa keperawatan di Universitas Udayana bulan April 2020, dapat dilihat bahwa responden mahasiswa keperawatan rata-rata berusia 20 tahun. Sebagian besar responden berjenis kelamin perempuan $(84,5 \%), \%)$. Mahasiswa keperawatan terbanyak berasal dari semester 2 dengan jumlah 44 orang $(29,7 \%)$. Tingkat pendidikan tertinggi orangtua responden, mayoritas berasal dari jenjang perguruan tinggi yang berjumlah 68 orang $(45,9 \%)$. Responden lebih banyak tidak mengalami masalah kesehatan dengan jumlah 106 $(71,6 \%)$, sedangkan responden yang mengalami masalah kesehatan berjumlah 42 orang $(28,4 \%)$.
Mayoritas responden menggunakan internet untuk tujuan kesehatan dengan frekuensi beberapa kali seminggu berjumlah 70 orang $(47,3 \%)$.

Tabel 3 menunjukkan bahwa sebanyak 9,5\% mahasiswa keperawatan di Universitas Udayana dengan health literacy yang tidak adekuat, 43,2\% bermasalah, 44,6\% cukup, dan 2,7\% sangat baik. Mayoritas mahasiswa keperawatan di Universitas Udayana dengan health literacy rendah (tidak adekuat atau bermasalah) dengan jumlah $52,7 \%$. Hanya sejumlah $47,3 \%$ dengan health literacy baik (cukup atau sangat baik).

Tabel 1

Health Literacy pada Mahasiswa Keperawatan di Universitas Udayana

\begin{tabular}{cccc}
\hline Variabel & Kategori & Frekuensi (n) & Persentase (\%) \\
\hline Health Literacy & Tidak adekuat & 14 & 9,5 \\
\cline { 2 - 4 } & Bermasalah & 64 & 43,2 \\
\cline { 2 - 4 } & Cukup & 66 & 44,6 \\
\cline { 2 - 4 } & Sangat baik & 4 & 2,7 \\
\cline { 2 - 4 } & Total & 148 & 100 \\
\hline
\end{tabular}

Tabel 4

Hasil Uji Korelasi

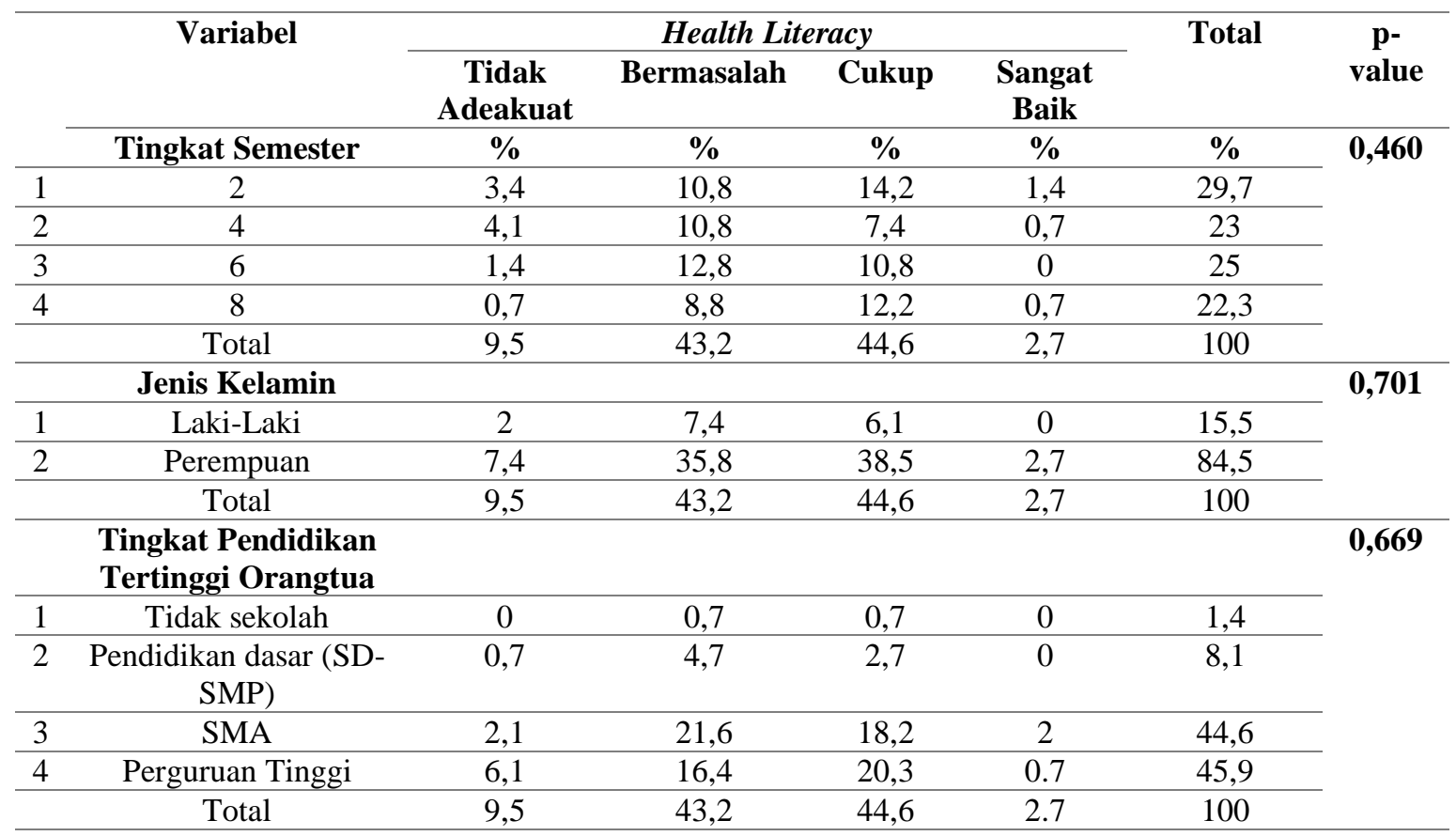




\begin{tabular}{|c|c|c|c|c|c|c|c|}
\hline & $\begin{array}{c}\text { Keberadaan Masalah } \\
\text { Kesehatan }\end{array}$ & & & & & & 0,232 \\
\hline 1 & $\mathrm{Ya}$ & 4,1 & 13,5 & 9,5 & 1,4 & 28,4 & \\
\hline \multirow[t]{3}{*}{2} & Tidak & 5,4 & 29,7 & 35,1 & 1,4 & 71,6 & \\
\hline & Total & 9,5 & 43,2 & 44,6 & 2,7 & 100 & \\
\hline & $\begin{array}{c}\text { Frekuensi } \\
\text { Penggunaan Internet } \\
\text { untuk Tujuan } \\
\text { Kesehatan }\end{array}$ & & & & & & $\mathbf{0 , 2 3 2}$ \\
\hline 1 & 1-3 kali sebulan & 1,4 & 10,8 & 4,7 & 0 & 16,9 & \\
\hline 2 & 1 kali seminggu & 1,4 & 2,7 & 4,1 & 0 & 8,1 & \\
\hline 3 & $\begin{array}{c}\text { Beberapa kali } \\
\text { seminggu }\end{array}$ & 4,7 & 42,2 & 48,5 & 2,7 & 44,6 & \\
\hline 4 & $\begin{array}{c}\text { Kurang dari } 3 \text { kali } \\
\text { sehari }\end{array}$ & 0 & 3,4 & 6,8 & 0 & 10,1 & \\
\hline \multirow[t]{2}{*}{5} & Lebih dari 3 kali sehari & 2 & 8,1 & 7,4 & 0 & 17,6 & \\
\hline & Total & 9,5 & 43,2 & 44,6 & 2.7 & 100 & \\
\hline
\end{tabular}

Hasil penelitian menunjukkan bahwa sebanyak $9,5 \%$ mahasiswa keperawatan di Universitas Udayana berada pada tingkat health literacy tidak adekuat, $43,2 \%$ bermasalah, $44,6 \%$ cukup, dan $2,7 \%$ sangat baik. Mayoritas mahasiswa keperawatan di Universitas Udayana dengan health literacy rendah (tidak adekuat atau bermasalah) dengan jumlah 52,7\%. Hanya sejumlah $47,3 \%$ dengan health literacy baik (cukup atau sangat baik).

Berdasarkan hasil penelitian dapat dilihat bahwa tidak terdapat hubungan yang signifikan antara tingkat semester, jenis kelamin, tingkat pendidikan tertinggi orangtua, keberadaan masalah kesehatan, dan frekuensi penggunaan internet untuk tujuan kesehatan dengan health literacy. Hasil uji penunjukkan p-value dari uji analisis tingkat semester, jenis kelamin, tingkat pendidikan tertinggi orangtua, keberadaan masalah kesehatan, dan frekuensi penggunaan internet untuk tujuan kesehatan dengan health literacy lebih dari $0,05(0,460,0,701,0,669$, $0,232,0,232)$ sehingga $\mathrm{H}_{0}$ diterima yang berarti tidak terdapat hubungan yang signigikan antara tingkat semester, jenis kelamin, tingkat pendidikan tertinggi orangtua, keberadaan masalah kesehatan, dan frekuensi penggunaan internet untuk tujuan kesehatan dengan health literacy.

\section{PEMBAHASAN}

Mahasiswa keperawatan di Universitas Udayana lebih banyak berada pada tingkat health literacy rendah (tidak adekuat atau bermasalah) dengan jumlah sebanyak 52,7\%. Hasil penelitian ini sejalan dengan sejumlah penelitian sejenis yang menyebutkan bahwa tingkat health literacy mahasiswa keperawatan mayoritas berada pada tingkat rendah (Erunal, et al., 2019; Ozen, et al., 2019).

Rendahnya health literacy pada mahasiswa keperawatan di Universitas Udayana dapat disebabkan karena mahasiswa merupakan kelompok dewasa awal dengan rentang usia 18-25 tahun yang memiliki anggapan memiliki status kesehatan yang baik (Lau \& Neinstein, 2017). Persepsi kelompok dewasa awal memiliki status kesehatan yang baik karena pada tahap kehidupan ini penyakit cenderung asimtomatik sehingga tidak dirasakan mengganggu kesehatan dan kehidupan sehari-hari (Bonnie, Stroud, \& Breiner, 2015). Persepsi sehat ini membuat mahasiswa keperawatan kurang memperhatikan status kesehatannya sehingga kurang aktif dalam pencarian 
informasi yang menyebabkan rendahnya health literacy.

Rendahnya health literacy pada mahasiswa keperawatan dapat disebabkan karena kurangnya pengetahuan mahasiswa keperawatan terkait health literacy. Tidak dimasukkannya health literacy ke dalam proses pembelajaran menjadikan mahasiswa kurang memiliki pengetahuan tentang istilah "health literacy" sehingga kurang kesadaran akan pentingnya health literacy terhadap kesehatan dan perannya sebagai perawat dimasa depan (Ozen, et al., 2019).

Tingkat semester tidak berhubungan dengan health literacy mahasiswa keperawatan di Universitas Udayana. Hasil penelitian di Universitas Udayana kontras dengan hasil penelitian sejenis yang menyebutkan semakin besar semester diikuti dengan meningkatnya health literacy mahasiswa keperawatan (Erunal, et al., 2019; Ozen, et al., 2019). Tidak adanya hubungan antara tingkat semester dan health literacy dapat disebabkan oleh Mahasiswa keperawatan di Universitas Udayana dari baik semester 2,4,6 atau 8 belum pernah mendapatkan pembelajaran spesifik yang membahas health literacy sehingga membuat mahasiswa keperawatan kurang menyadari pentingnya health literacy dan tidak mengetahui cara meningkatkan health literacy (McCleary-Jones, 2012).

Jenis kelamin tidak memiliki hubungan dengan health literacy pada mahasiswa keperawatan dapat disebabkan karena mahasiswa berpersepsi memiliki status kesehatan yang optimal sehingga baik laki-laki dan perempuan kurang memerhatikan kesehatan (Bonnie, et al., 2015). Penelitian yang dilakukan oleh Ayaz Alkaya \& Terzi (2019) juga menunjukkan hasil yang sama, disebutkan bahwa jenis kelamin tidak berhubungan dengan health literacy mahasiswa keperawatan.
Hasil penelitian pada mahasiswa keperawatan di Universitas Udayana juga menunjukkan bahwa tingkat pendidikan tertinggi orangtua tidak berhubungan dengan health literacy, penemuan ini kontras dengan penelitian sejenis yang menyebutkan bahwa orangtua dengan tingkat pendidikan yang lebih tinggi membuat anaknya memiliki tingkat health literacy baik (Zhang et al., 2016). Orangtua dengan pendidikan yang lebih tinggi membuat mahasiswa memiliki pemahaman yang lebih baik mengenai informasi kesehatan, namun untuk penerapan informasi bergantung kepada mahasiswa itu sendiri sehingga tingkat pendidikan orangtua tidak berhubungan dengan health literacy pada mahasiswa keperawatan (Holt, et al., 2020).

Faktor keberadaan masalah kesehatan dan penggunaan internet untuk tujuan kesehatan juga ditemukan tidak berhubungan dengan health literacy. Temuan ini kontras dengan hasil penelitian sejenis yang menyebutkan bahwa mahasiswa keperawatan yang memiliki kesehatan dan menggunakan internet memiliki health literacy yang lebih tinggi (Ayaz-Alkaya \& Terzi, 2019). Mahasiswa merupakan kelompok dewasa awal yang merasa bahwa masalah kesehatannya tidak bersifat mengancam kehidupannya sehingga mahasiswa tidak terlalu perhatian dengan masalah kesehatan yang dialaminya (Febriani, 2019).

Tidak adanya hubungan antara frekuensi penggunaan internet untuk tujuan kesehatan dengan health literacy dapat disebabkan karena ketidakmampuan mahasiswa keperawatan dalam menilai informasi yang berkualitas tinggi atau rendah (Park \& Lee, 2015). Ketidamampuan mahasiswa keperawatan untuk menilai suatu informasi berkualitas atau tidak dapat membuat mahasiswa keperawatan melakukan kesalahan dalam penggunaan informasi yang kurang akurat 
sehingga berdampak terhadap status kesehatanya sehingga frekuensi penggunaan internet untuk tujuan kesehatan tidak berhubungan dengan health literacy pada mahasiswa keperawatan.

Keterbatasan penelitian adalah pendekatan cross-sectional digunakan pada penelitian sehingga hubungan sebab akibat tidak dapat melihat hubungan sebab akibat antar variabel secara langsung

\section{SIMPULAN DAN SARAN}

Mahasiswa keperawatan di Universitas Udayana mayoritas dengan health literacy rendah (tidak adekuat atau cukup) dengan jumlah 52,7\%. Tingkat semester, jenis kelamin, tingkat pendidikan tertinggi orangtua, keberadaan masalah kesehatan, dan frekuensi penggunaan internet untuk tujuan kesehatan tidak memiliki hubungan yang signifikan dengan health literacy pada mahasiswa keperawatan di Universitas Udayana.

Berdasarkan hasil penelitian, disarankan kepada tenaga pengajar untuk mempertimbangkan memasukan konten health literacy ke dalam pembelajaran mahasiswa keperawatan di Universitas Udayana untuk membantu mahasiswa keperawatan memperdalam pemahaman pentingnya health literacy. Peneliti selanjutnya juga diharapkan dapat mengkaji faktor-faktor lain yang dapat berhubungan dengan health literacy pada mahasiswa keperawatan atau mengembangkan intervensi untuk meningkatkan health literacy pada mahasiswa keperawatan di Universitas Udayana.

\section{DAFTAR PUSTAKA}

Ayaz-Alkaya, S., \& Terzi, H. (2019). Investigation of Health Literacy and Affecting Factors of Nursing Students. Nurse Education in
Practice, 34, 31-35.doi: 10.1016/j.nepr.2018.10.009

Bonnie, R. J., Stroud, C., \& Breiner, H. (2015). Young Adults in the $21^{\text {st }}$ Century. National Academies Press (US). Retrieved from: https://www.ncbi.nlm.nih.gov/boo ks/NBK284782/

Duong, T. V., Aringazina, A., Baisunova, G., Nurjanah, Pham, T. V., Pham, K. M., Truong, T. Q., Nguyen, K. T., Oo, W. M., Mohamad, E., Su, T. T., Huang, H.-L., Sørensen, K., Pelikan, J. M., Van den Broucke, S., \& Chang, P. W. (2017). Measuring Health Literacy in Asia: Validation of the HLS-EUQ47 Survey Tool in Six Asian Coutries. Journal of Epidemiology, 27(2), 80-86. doi: 10.3928/24748307-20190225-01

Erunal, M., Ozkaya, B., Mert, H., \& Kucukguclu, O. (2019). Investigation of Health Literacy Levels of Nursing Students and Affectiong Factors. 11(3), 11.

Febriani, W. M. (2019). Gambar Perilaku Pencarian Pengobatan pada Mahasiswa Fakultas Kesehetan Masyarakat di Universitas Airlangga, Jurnal PROMKES, 7(2), $193 . \quad$ doi: 10.20473/jpk.V7.I2.2019.193-203

Holt, K. A., Overgaard, D., Engel, L. V., \& Kayser, L. (2020). Health Literacy, Digital Literacy, and eHealth Literacy in Danish Nursing Students at Entry and Graduate Level: A Cross Sectional Study, BMC Nursing, 19(1), 22. doi: 10.1186/s12912-020-00418$\mathrm{W}$

Kennard, D. K. (2016). Health Literacy Concepts in Nursing Education. 2.

Kickbusch, I., Pelikan, J. M., Apfel, F., \& Tsouros, A. D. (2013). Health literacy: The solid facts. World 
Health Organization Regional Office for Europe.

Kolnik, T. Š., Hozjan, D., \& Babnik, K. (2017). Health Literacy and Health Related Lifestyle Among Nursing Students. Pielegniarstwo XXI Wieku / Nursing in the 21st Century, 16(2), 42-46. doi: 10.1515/pielxxiw-2017-0017

Lau, J. S., \& Neinstein, L. (2017). Young Adult Health and Well-Being: A Position Statement of the Society for Adolescent Health and Medicine. Journal of Adolescent Health, 60(6), 758-759. doi: 10.1016/j.jadohealth.2017.03.021

McCleary-Jones, V. (2012). Assessing Nursing Students' Knowledge of Health Literacy: Nurse Educator, 37(5), 214-217. doi: 10.1097/NNE.0b013e318262ead3

Ozen, N., Bal Ozkaptan, B., Coskun, S., \& Terzioglu, F. (2019). Health Literacy of Nursing Students and Its Effective Factors. Nursing Forum, 54(3), 396-402. doi: $10.1111 /$ nuf. 12346

Park, H., \& Lee, E. (2015). Self-reported eHealth Literacy among Undergraduate Nursing students in South Korea: A pilot study. Nurse Education Today, 35(2), 408-413. doi: 10.1016/j.nedt.2014.10.022

Setyawan, M. B. (2017). Hubungan Penggunaan Smartphone dengan Health Literacy pada Perawat di RSU Haji Surabaya. Universitas Gajah Mada.

Sørensen, K., Van den Broucke, S., Fullam, J., Doyle, G., Pelikan, J., Slonska, Z., \& Brand, H. (2012). Health Literacy and Public Health: A Systematic Review and Integration of Definitions and Models. BMC Public Health, 12(1), 80. doi: 10.1186/14712458-12-80
Uysal, N., Ceylan, E., \& Koç, A. (2019). Health Literacy Level and Influencing Factors in University Students. Health \& Social Care in the Community. doi: 10.1111/hsc. 12883

Zhang, Y., Zhang, F., Hu, P., Huang, W., Lu, L., Bai, R., Sharma, M., \& Zhao, Y. (2016). Exploring Health Literacy in Medical University Students of Chongqing, China: A Cross-Sectional Study. PLOS ONE, 11(4), e0152547. doi: 10.1016/S0140-6736(16)32026-8 